\title{
AN ALTERNATIVE METHODOLOGY FOR DELIVERING HEAVY LUGGAGE'S FROM BAGGAGE CAROUSEL USING RFID SYSTEM
}

\author{
I. Aadil Mohamed \\ Department of Mechanical Engineering \\ Rajalakshmi Engineering College, Chennai, \\ Tamil Nadu, India \\ Abishek.G \\ Department of Mechanical Engineering \\ Rajalakshmi Engineering College, Chennai, \\ Tamil Nadu, India
}

\author{
Amritha.N \\ Department of Mechanical Engineering \\ Rajalakshmi Engineering College, Chennai, \\ Tamil Nadu, India \\ Aditya.B.J \\ Department of Mechanical Engineering \\ Rajalakshmi Engineering College, Chennai, \\ Tamil Nadu, India
}

\author{
Sakthivel.S \\ Department of Mechanical Engineering \\ Rajalakshmi Engineering College, Chennai, \\ Tamil Nadu, India
}

\begin{abstract}
Baggage carousel is a device at an airport, that delivers checked luggage to the passengers at the baggage reclaim area. This device plays a major role in the baggage handling system (BHS) in airports. In the current handling system, passengers carrying heavy load or senior citizens find it difficult to carry their luggage and place it in the trolley (as the baggage remains in a circulating movement along the carousel). Thus, this article provides an alternate methodology to sort the heavy luggage in the baggage carousel using RFID system. The luggage can then be loaded on a hydraulic trolley. The hydraulic trolley can be adjusted to the required height using the pedal attached at the bottom of the trolley. Hence, a system is provided where the concerned passenger does not require to carry the luggage at any circumstance.
\end{abstract}

Keywords-Baggage carousel, baggage reclaim area, baggage handling system, RFID system.

\section{INTRODUCTION}

With a rapid rate of growth in technologies over two decades, the advancement and development of airport management systems have led to the replacement of manual baggage handling to a semi-automated handling system. Its termed as "baggage handling system "(BHS). Baggage handling system carries out a significant operation in the airports. The entire checking and transportation of the luggage from the check-in counter till the baggage reclaim area is handled by the BHS. It performs a wide range of operations such as detecting, tracking, redirecting and so on. The operation that we are focusing here is sorting of the luggage. With increasing passenger traffic in airports, there are higher possibilities of failure in crowd management due to increase in the proximity of passenger arrivals and departures. The flexibility of crowd management in the airports can be achieved through a properly designed baggage handling system considering various factors such as frequency of flights, passenger count, proximity level and many more.

Feasibility of passengers is another factor to be considered. In general, when the luggage is in circulation along the carousel, the elderly and the passengers with heavy luggage find it difficult to shift their luggage from the carousel to the trolley. Thus, this article focuses on the problems caused to the passengers in such conditions and provides a suitable solution. The operations carried out by the provided system are as follows:

1. Allotment of RFID tags

2. Sorting process

3. Arrival of luggage at baggage carousel

4. Identification of luggage

5. Delivery through an extension in the carousel

6. Loading and unloading of luggage using hydraulic trolley

\section{PROBLEM IDENTIFICATION}

In general, it was found that a person carrying a load in one hand poses more load on the lower back than carrying twice as much that amount but distributed evenly between both hands. 
In addition, carrying a load in hands held against chest is corresponding to a higher heart rate than dividing the same weight evenly in two grocery bags carried in hands on the both body sides.[1] In airports, a senior citizen or a person with medical requirements has to lift his/her baggage from a moving baggage carousel. This pressure in the spinal cord is transmitted to various parts of the body. Some of the major muscle group that are affected are gluteus maxima, trapezius, hamstring and all of the forearm muscles.[2] This is due to the displacement of the centre of gravity of the body from its original position. And even more sudden application of load unevenly may lead to snapping or breaking of bones. If a person injures his/her back once, there is $80 \%$ chance of re-injuring his/her back again in the future.

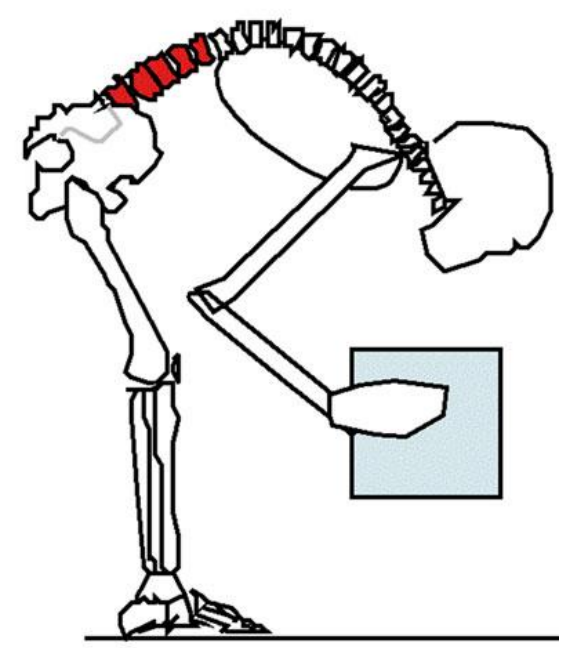

Fig. 1. shows the effect of lifting a heavy object on the spinal cord.[3]

The muscles located along with the spine are in their strongest position when the three curves of the spine maintained properly. When lifting a heavy luggage with a poor posture, it can put a great deal of stress on the lower back muscles and when the demand is too on a muscle it can be injured. Also, the compression on the discs is also uneven. In senior citizens the problem of osteoarthritis complicates it and hence lifting heavy weights can easily strain their backs.

\section{COMPARISON OF LOAD IMPACT}

The ELC is a progressive isoinertial test of lift-lower capacity that uses masked free weights to allow retest confirmation of full effort. A series of progressive loads over three vertical ranges at two frequencies is used, and the evaluee's maximum acceptable weight is recorded at each range. In general, the ELC begins at 10 pounds and progresses in 10-pound increments, using color-coded blind weights. The evaluee is not made aware of the starting and incremental loads. The ELC frequency begins at one lift per cycle for each of the three vertical ranges and proceeds to four lifts per cycle for each range if the evaluee is capable.

It is a six-stage progressive test of lift capacity developed by a team headed by Leonard Matheson, $\mathrm{PhD}$, and is specifically designed to evaluate persons with medical impairments. The ELC test is backed by an ongoing program to develop and provide normative data to set treatment goals and identify full effort.

The ELC is the only lift capacity test that offers norms for men and women of various ages based on peer-reviewed published research. No other test comes close. Although the PILE and WEST both offer normative data, the norms are quite limited and have no age grading. [4] Since, this alternate method was proposed considering the age factor and the liftable capacity ,ELC was chosen as the test analyses and tabulates based on both age and gender.

The ELC was conducted on a blind basis beginning with an empty crate at $4.5 \mathrm{~kg}(10 \mathrm{lbs})$ and increasing in $4.5 \mathrm{~kg}$ increments (loaded by the evaluator) for all evaluees. The frequency of the ELC is one lift per cycle or four lifts per cycle, depending on the subtest.

Table -1 ELC Test performance [5]

\begin{tabular}{|c|c|c|c|c|c|c|c|c|}
\hline \multirow[b]{3}{*}{ Subtest } & \multicolumn{4}{|c|}{ Male } & \multicolumn{4}{|c|}{ Female } \\
\hline & \multicolumn{2}{|c|}{ Test } & \multicolumn{2}{|c|}{ Retest } & \multicolumn{2}{|c|}{ Test } & \multicolumn{2}{|c|}{ Retest } \\
\hline & Mean & SD & Mean & SD & Mean & SD & Mean & SD \\
\hline 1 & 33.74 & 7.74 & 33.88 & 7.82 & 19.54 & 5.79 & 19.89 & 6.13 \\
\hline 2 & 38.50 & 8.26 & 38.33 & 8.29 & 24.70 & 7.18 & 24.56 & 7.36 \\
\hline 3 & 34.24 & 7.80 & 34.34 & 7.77 & 19.29 & 5.82 & 19.67 & 5.80 \\
\hline 4 & 27.74 & 6.83 & 28.20 & 6.97 & 15.82 & 5.07 & 16.34 & 5.05 \\
\hline 5 & 31.26 & 7.93 & 31.77 & 7.69 & 19.44 & 6.43 & 20.03 & 6.94 \\
\hline 6 & 26.39 & 7.28 & 27.07 & 6.91 & 14.86 & 5.20 & 15.51 & 5.09 \\
\hline
\end{tabular}

A series of one-way analysis of variance based on gender demonstrated a significant difference in terms of maximum acceptable weight for all six subtests in the ELC battery on both the test and retest.

Table -2 Lift Capacity :subset classification [5]

\begin{tabular}{|c|c|c|c|c|c|c|c|c|c|c|c|c|c|}
\hline & \multirow[b]{2}{*}{ Age (years) } & \multicolumn{2}{|c|}{ Sub-test I } & \multicolumn{2}{|c|}{ Sub-test 2} & \multicolumn{2}{|c|}{ Sub-test 3} & \multicolumn{2}{|c|}{ Sub-test 4} & \multicolumn{2}{|c|}{ Sub-test 5} & \multicolumn{2}{|c|}{ Sub-test 6} \\
\hline & & Mean & SD & Mean & SD & Mean & SD & Mean & SD & Mean & SD & Mean & SD \\
\hline \multirow[t]{5}{*}{ Male } & $15<30$ & 34.4 & 7.4 & 39.1 & 7.9 & 35.0 & 7.6 & 28.3 & 6.6 & 32.0 & 7.5 & 27.0 & 7.3 \\
\hline & $30<40$ & 33.7 & 7.7 & 38.5 & 8.2 & 34.1 & 7.6 & 27.6 & 6.8 & 31.1 & 8.0 & 26.3 & 7.3 \\
\hline & $40<50$ & 33.4 & 7.9 & 38.1 & 8.5 & 33.5 & 7.8 & 27.6 & 7.2 & 30.8 & 8.5 & 25.3 & 7.4 \\
\hline & $50<60$ & 28.9 & 8.5 & 33.5 & 9.2 & 29.5 & 8.8 & 23.7 & 7.4 & 25.7 & 8.8 & 20.5 & 8.8 \\
\hline & $60+y r s$ & 25.1 & 6.9 & 31.5 & 10.3 & 26.6 & 8.3 & 20.2 & 7.2 & 21.4 & 9.7 & 17.9 & 7.0 \\
\hline \multirow[t]{5}{*}{ Female } & $15<30$ & 19.8 & 5.7 & 25.3 & 7.0 & 19.6 & 5.7 & 15.9 & 5.0 & 19.9 & 6.3 & 15.0 & 5.1 \\
\hline & $30<40$ & 19.9 & 5.7 & 25.1 & 7.1 & 19.6 & 5.7 & 16.3 & 5.2 & 19.8 & 6.4 & 15.1 & 5.6 \\
\hline & $40<50$ & 18.3 & 5.7 & 22.3 & 7.3 & 17.6 & 5.9 & 14.7 & 5.2 & 17.4 & 6.5 & 13.3 & 5.5 \\
\hline & $50<60$ & 16.9 & 6.0 & 20.6 & 7.1 & 16.5 & 6.3 & 13.2 & 5.7 & 15.6 & 6.7 & 12.3 & 6.4 \\
\hline & $60+y r s$ & 17.4 & 5.2 & 20.0 & 7.5 & 16.5 & 5.5 & 13.2 & 4.6 & 15.3 & 5.6 & 12.2 & 4.5 \\
\hline
\end{tabular}

Performance in the ELC subtests was studied in terms of both age and gender, the results of which are presented in Table 8. Main effects for both age group and gender are found for each of the subtests, (all p < 0.001).[5] An important use of the ELC data is to determine the adequacy of a person's lift capacity for his or her job's demands. And the values obtained from the above tabulation concluded that on an average, the liftable 
weight for an age group of $(60+\mathrm{yrs})$ was found to be $23.78 \mathrm{~kg}$ and $15.76 \mathrm{~kg}$ for male and female gender respectively.

\section{METHODOLOGY}

This section provides a brief description of the newly proposed baggage carousel which was used to solve the problem mentioned above.

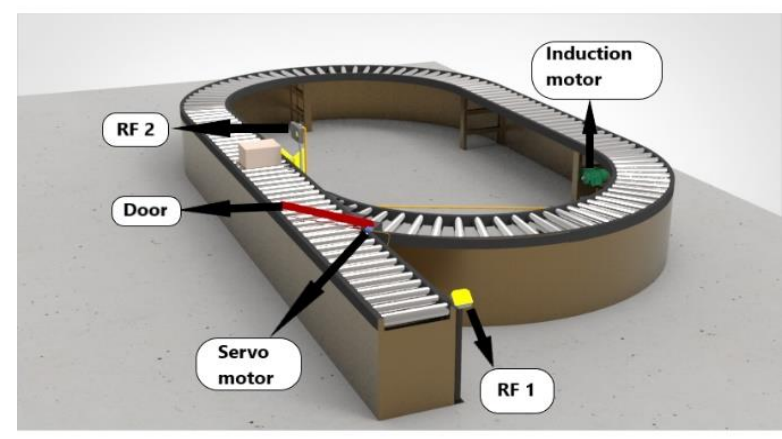

Fig. 2. Image of newly proposed baggage carousel

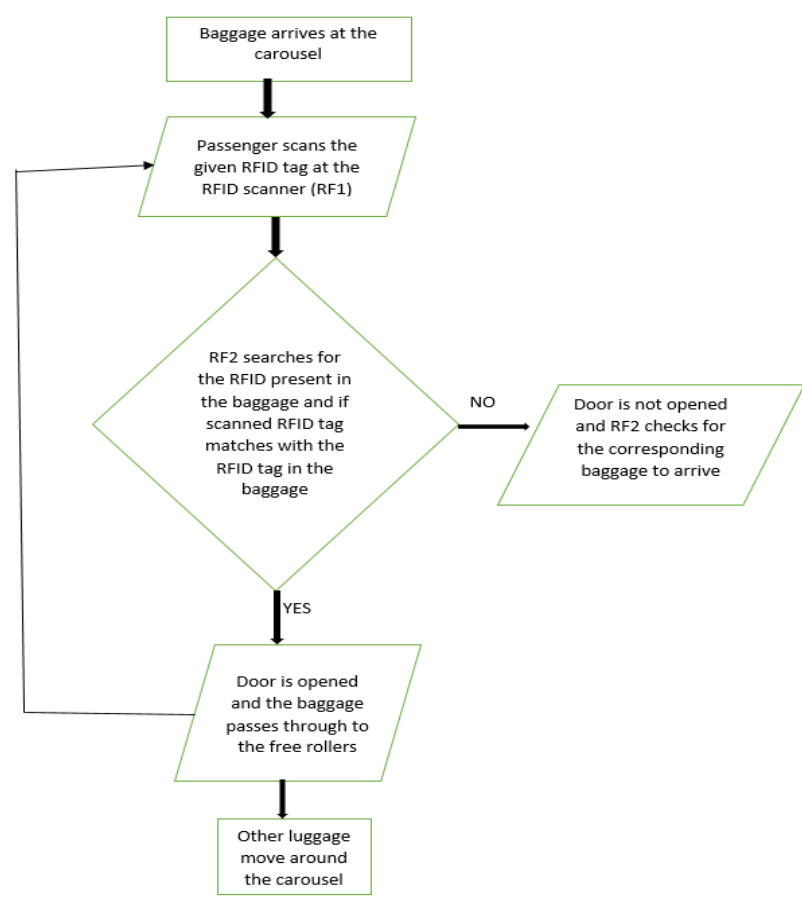

Fig. 3.flow diagram of the proposed baggage carousel

Fig (3)-represents the newly proposed baggage carousel based on belt driven roller conveyor system. RF 1 and RF 2 represents the two RFID readers in which one is touchscreen reader and the other is a long range reader. Two RFID tags where both have unique ID's but same code, will be given to the passenger in which one will be attached to the baggage and the other will be given to the passenger. When the passenger arrives at the reclamation area, he/she will place the given RFID tag at the RFID reader. This information will be passed to the processor. The long range RFID reader ( RF 2) will search for the other RFID tag which is attached to the baggage. Once the other RFID tag is found and the two codes of RFID tags match, the door is opened which is represented by $\mathrm{D}$. The baggage passes through the door to reach the free rollers, from where the passenger can manually pull his/her baggage to the hydraulic trolley.

\section{A. Selection of conveyor system-}

A conveyor system is a handling equipment which helps to move materials from one location to other. Conveyor systems are usually very popular is packaging and material handling industries. Conveyor systems are also used in airports in baggage handling processes and baggage delivery. The conveyor system used in baggage delivery is also called as baggage carousel. There are almost 20+ types of conveyor systems namely chain conveyor, gravity conveyor, flexible conveyor, gravity skate wheel conveyor, vibrating conveyor, vertical conveyor, pneumatic conveyor and so on. For the proposed method belt driven roller conveyor system is used. A $\mathrm{u}$-shaped with a straight extension roller conveyor is used.

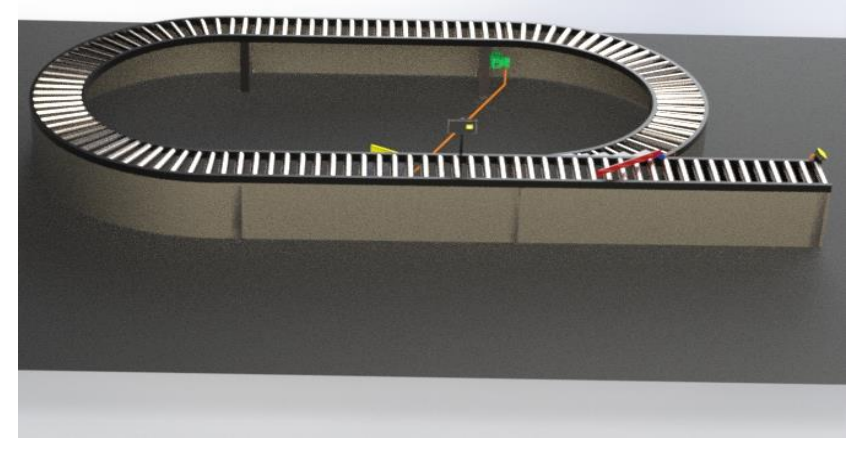

Fig. 4. Image of the belt driven roller conveyor

This type of conveyor system was chosen because it provides effective horizontal transportation, less friction between the baggage and the rollers, the speed of the process can be controlled easily and as the parts never touch each other the risk of damage is also low. Also the concept of this paper can be easily applied on this system.

\section{$B$. Selection of motor-}

In this proper, two types of motors are used. Basically an electrical machine which converts electrical energy to mechanical energy is called as electric motor. Electric motors can be powered by direct current (DC) sources, such as from batteries, motor vehicles or rectifiers, or by alternating current 
(AC) sources, such as a power grid, inverters or electrical generators.

The two types of motors used in this project are:

1. Induction motor - for the roller drive

2. Servo motor - for door opening and closing

\section{B.1. Induction Motor-}

An induction motor or asynchronous motor is an AC electric motor in which the electric current in the rotor needed to produce torque is obtained by electromagnetic induction from the magnetic field of the stator winding. An induction motor's rotor can be either wound type or squirrel-cage type. In this project, induction motor is used to drive the rollers using belt driven system.

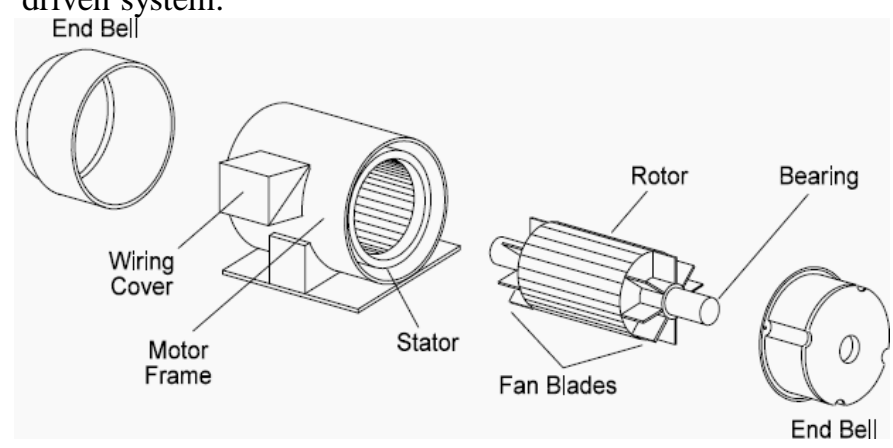

Fig. 5. shows the sectional view of the induction motor. [6]

Reasons why induction motor is used over other motors is listed below.

- Induction motors are simple and rugged in construction.

- They are robust and can operate in any environmental condition.

- Induction motors are cheaper in cost due to the absence of brushes, commutators, and slip rings.

- They are maintenance free motors unlike dc motors and synchronous motors due to the absence of brushes, commutators and slip rings.

- Induction motors can be operated in polluted and explosive environments as they do not have brushes which can cause sparks

- 3 phase induction motors will have self-starting torque unlike synchronous motors, hence no starting methods are employed unlike synchronous motor. However, single-phase induction motors does not have self-starting torque, and are made to rotate using some auxiliaries.

- Induction motors make them more prominent in industrial and domestic applications.

\section{B.2. Servo Motor-}

Servo motor is a closed-loop servomechanism that uses position feedback to control its motion and final position. The input to its control is a signal (either analogue or digital) representing the position commanded for the output shaft. The motor is paired with some type of position encoder to provide position and speed feedback. In the simplest case, only the position is measured. The measured position of the output is compared to the command position, the external input to the controller. If the output position differs from that required, an error signal is generated which then causes the motor to rotate in either direction, as needed to bring the output shaft to the appropriate position. As the positions approach, the error signal gets reduced to zero and the motor stops. The very simplest servomotors use position-only sensing via a potentiometer and bang-bang control of their motor; the motor always rotates at full speed (or is stopped). This type of servomotor is not widely used in industrial motion control, but it forms the basis of the simple and cheap servos used for radio-controlled models. In this paper a servo motor is used to control the opening/ closing of the door (D).

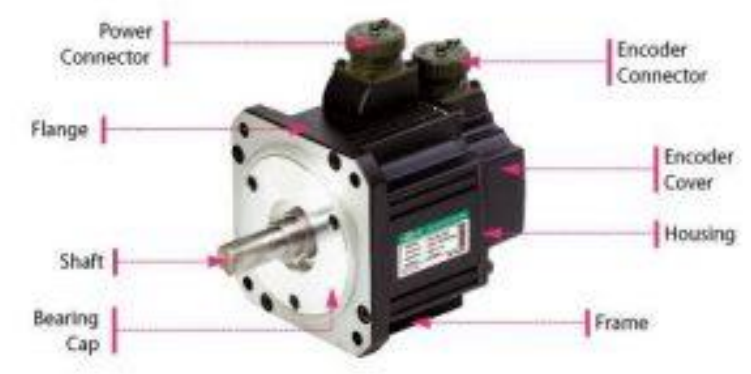

Fig. 6.Image of the servo motor used [7]

Reasons why servo motor was used for the operating the door over other motors is listed below:

- High output power relative to motor size and weight.

- Encoder determines accuracy and resolution.

- High efficiency. It can approach $90 \%$ at light loads.

- High torque to inertia ratio. Servo Motors can rapidly accelerate loads.

- Has 2-3 times more continuous power for short periods.

- Has 5-10 times more rated torque for short periods.

- Servo motors achieve high speed sat high torque.

\section{Selection of RFID-}

Radio Frequency Identification (RFID) is a wireless communication which uses electromagnetic or electro static coupling in radio frequency portion of the electromagnetic spectrum to identify objects. [8] In RFID digital data that encoded in RFID tags are captured using RFID readers. RFID 
does all this by AIDC (Automatic Identification and Data Capture) method. This method automatically identifies objects, collects data and enters those into computer system with little or no need of human. RFID system is an easier way to capture and store data. Compared to barcode there is no need to place it in a particular place to capture the data. The process is faster so the productivity is higher.

The components in an RFID system are RFID tag, RFID reader and antenna. RFID tags contain an integrated circuit and an antenna. These tags used to transmit data to the RFID reader. This is then converted into more usable form of data by the reader. The collected information from the tags is then transferred through a communications interface to a host computer system. The data stored in the computer can be used later.

RFID are classified based on the frequency and how the tag communicates with the reader:

Based on the range of frequency they use to communicate the data

- $\quad$ Low Frequency (LF) (up to $10 \mathrm{~cm}$ )

- High Frequency (HF) (10 cm to $1 \mathrm{~m})$

- Ultra-High Frequency (UHF) (up to $12 \mathrm{~m}$ )

Based on how the tags communicate with the reader:

- Active RFID

- $\quad$ Passive RFID

\section{C.1. PASSIVE RFID TAG -}

A passive RFID tag does not contain a battery. The power is supplied by the RFID reader. When the RFID reader sends radio waves to the coiled antenna in the passive RFID tag forms a magnetic wave. The tag energizes circuit in it. Then the information encoded in the tag memory is sent to the reader. Then this information is sent to the processor where it looks whether the two RFID codes match in order to open the door. The advantages of passive RFID system are:

- It is cheaper than active RFID system

- It automates data collection

- Tags are detected instantly.

- It does not contain internal power source

\section{2 RFID SYSTEM OPERATIONS -}

In a passive RFID system the RFID reader supplies the tag with essential power so as for it to perform modulation of the reader's interrogation signal. Tags are also known as transponders. Therefore, the reader and transponders are in a master-slave relationship where the reader acts as a master and thus the transponders as slaves. Nevertheless RFID readers themselves are during a slave position also. A software application, also called middleware, processes data from the RFID reader, acts because the master unit and sends commands to the reader. This means that each one activities of the reader and transponder are initiated by the appliance software. In a hierarchical system structure the appliance software like enterprise software represents the master while the reader, because the slave, which is merely activated when it receives a command from the appliance software, and therefore, the reader perform read or write operations of RFID transponders that are in its interrogation area.

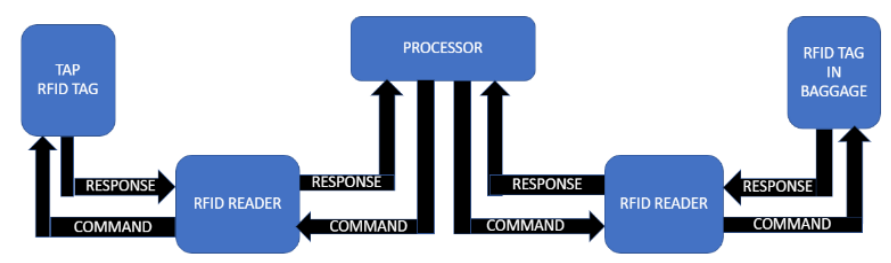

Fig. 7.Image represents functioning of the RFID system

In the proposed Baggage carousel system two types of RFID readers ( $R F 1 \& \mathrm{RF} 2)$ are used. They are:

- A tap RFID reader (RF1) with low frequency (up to 10 $\mathrm{cm}$ ), which will be present at the end of the extension, the passive RFID tag which is given to the passengers at the check-in counter should be placed at this reader. The unique code in the RFID tag will be sent to the reader and further to the processor.

- $\quad$ A high frequency (10cm to $1 \mathrm{~m})$ RFID reader (RF2) is used to detect RFID tags which is present in the baggage.

\section{Hydraulic Trolley-}

Hydraulic trolley is a device used for lifting heavy loads by the application of much smaller force. It is based on Pascal's law, which states that intensity of pressure is transmitted equally in all directions through a mass of fluid at rest.[9] The loading capacity for this trolley is approximately $100-150 \mathrm{~kg}$ with an adjustable frame control using hydraulic cylinder. The cylinder is provided with a hydraulic fluid in it and is connected to the pedal and the frame. The frame is being attached to the main body of the trolley using a scissor jack for easy adjustment of the height in the trolley.

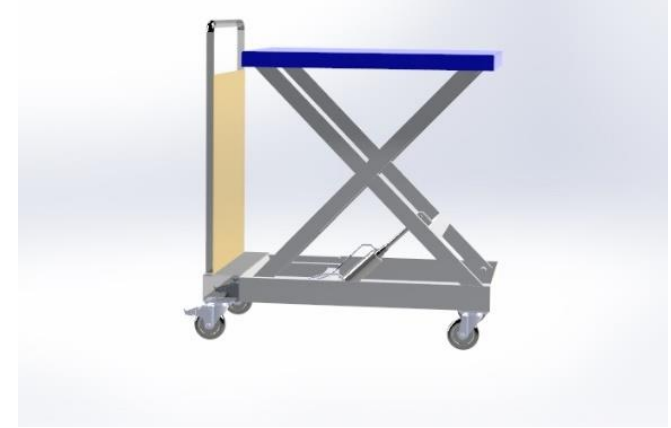

Fig. 8.Image of newly designed Hydraulic Trolley 
The trolleys which are currently available in airports are fixed with certain height and in such case, the passenger have to lift the luggage in order to place it in the trolley. Whereas, the purpose of the proposed methodology is to provide a convenient way for the people requiring physical assistance and/or the elderly in the baggage reclamation. Thus, usage of a hydraulic trolley would be best suited. The trolley can be adjusted according to the required height without much effort. A pedal is attached at the bottom of the trolley for the adjustment of height in the trolley. The force given to the pedal is proportional to the height being raised. A hydraulic cylinder is attached to the pedal where the main action takes place. The hydraulic fluid in the cylinder gets compressed as the pressure is applied on the pedal which ultimately results in the lift of the trolley frame being attached to the scissor jack.

Since, the category of passenger being considered here cannot apply much effort, the trolley is provided with certain features accordingly:

- The frame on which the luggage is to be loaded is made of a lighter metal. Hence, application of much pressure is not required in order to adjust the height.

- The wheels are of a fiber material in order to provide more friction in the movement. Therefore, the movement of the trolley would also be controlled that is, with a lesser speed being available through these wheels.

- Moreover usage of hydraulic method is specifically required as the reduction of height requires much lesser effort than that of increasing the height, compared to other methods of lifting.

The hydraulic trolley contributes a major role in the proposed system or methodology as it allows the passenger to transport their luggage from the conveyor to their vehicle. Since, the height can be adjusted accordingly, just the shifting of the luggage to and from the trolley in the same level is required. In short, the effort of loading and unloading heavy luggage is cut short for the passengers.

\section{CONCLUSION}

The goal identified for this project is to propose an alternative methodology for senior citizens and passengers with medical need, to claim their baggage from the baggage carousel at the reclamation area efficiently without putting much efforts to lift and place their baggage on the trolley. In the current baggage handling system, the luggage is sent on the baggage carousel which remains in continuous movement along the belt. the passengers have to lift their respective luggage from the belt to place it in the fixed airport trolley provided in the airports. On the other hand, the proposed methodology consists of a modified baggage carousel with an extension based on belt driven roller conveyor, RFID system and hydraulic trolley where the efforts for lifting the baggage from a moving baggage carousel for a senior citizen or passengers with medical need can be minimized. As a result, the proposed methodology provides a way for the concerned passengers to load and unload their luggage without much effort (preventing the effects imposed on their health due to the load). In other words, this methodology would be an extended hand of help in the airports being provided to the elderly and the people requiring assistance in reclamation of heavy luggage.

\section{REFERENCE}

[1] Mcgill, Stuart \& Marshall, Leigh \& Andersen, Jordan, (2013), "Low back loads while walking and carrying: Comparing the load carried in one hand or in both hands", Ergonomics. 56. 10.1080/00140139.2012.752528.

[2] https://www.researchgate.net/post/What_muscles_are_inv olved_in_lifting_and_carrying_boxes

[3] https://cached.forges.forumpa.it/assets/Speeches $/ 24787 / \mathrm{w}$ s120_depetris carlo_slides.pdf

[4] https://www.epicrehab.com/products/productsbackground/epic-lift-capacity-test-elc/

[5] Matheson, Leonard \& Verna, Joe \& Dreisinger, Thomas \& Leggett, Scott \& Mayer, John, (2013), "Age and gender normative data for lift capacity", Work (Reading, Mass.). 49. 10.3233/WOR-131671.pp258-264.

[6] https://electrical-engineering-portal.com/construction-of3-phase-ac-induction-motors.

[7] https://engineering.eckovation.com/servo-motor-typesworking-principle-explained/.

[8] https://www.massgroup.com/rfid-radio-frequencyidentification/

[9] M.Mamta Panchariya, , . "Advanced Airport Baggage System", Volume 5, Issue IV, International Journal for Research in Applied Science and Engineering Technology (IJRASET), ISSN : 2321-9653.Pages: 1568-1570.

[10] Georgy Olenin, 2016, "Design of hydraulic scissors lifting platform",Saimaa University of Applied Sciences, Faculty of Technology Lappeenranta, Degree Programme in Mechanical Engineering and Production Technology, Thesis 2016

[11] Transportation Security Administration, Planning Guidelines and Design Standards for Checked Baggage Inspection Systems Version 1.0, October 10, 2007 TSA506,pp.4-3,4.

[12] D. Balakrishna,A.Raghuram,2014," RFID Based Airport Luggage Checking and Tracking System using GSM Technology", ISSN 2319-8885 Vol.03,Issue.31, October2014, Pages:6279-6284. 